\title{
Iron Rod Penetrating Head Injury in a Child
}

\author{
Batuk Diyora ${ }^{1}$ Sagar Gawali ${ }^{1} \quad$ Mehool Patel $^{1} \quad$ Gagan Dhall ${ }^{1}$
}

1Department of Neurosurgery, Lokmanya Tilak Municipal General Hospital, Sion, Mumbai, India

Indian J Neurotrauma 2021;18:148-149.

\begin{abstract}
Address for correspondence Batuk Diyora, DNB, Department of Neurosurgery, Second Floor, College Building, Lokmanya Tilak Municipal General Hospital, Sion, Mumbai 400022, India (e-mail: bddiyora@gmail.com; batuk73@yahoo.co.in).
\end{abstract}

\begin{abstract}
Keywords

- penetrating injury

- children

- head injury

- iron rod

- trauma

Civilian penetrating brain injury (PBI) is a rare form of traumatic brain injury ( $\mathrm{TBI}$ ) and is rarer in the pediatric population. Pediatric PBI due to various objects has been reported in the literature. Pediatric PBI with an iron rod has not been previously described. We reported a case of civilian penetrating injury in a 6-year-old girl child patient who fell over a projecting iron rod at a construction site from a height of 6 to 8 feet. She was lifted off from the iron rod and taken to the emergency medical services. CT scan of the brain revealed linear intracerebral hemorrhage along the iron rod's track with a depressed fracture. She underwent emergency surgery because of a compound depressed fracture. She recovered well from his injury without neurological deficit with an excellent clinical outcome.
\end{abstract}

Penetrating brain injury (PBI) is a form of traumatic brain injury (TBI) where penetrating objects cause injury to brain parenchyma. Civilian PBI is a rare form of TBI and is rarer in the pediatric population. ${ }^{1}$ PBI is commonly seen in war conflicts resulting from high-velocity missiles and bullets. Civilian PBI is a low-velocity injury resulting from bizarre objects. ${ }^{2,3}$

We reported a case of civilian penetrating injury in a 6-year-old girl child patient who fell over a projecting iron rod at a construction site from a height of 6 to 8 feet. She was lifted off from the iron rod and taken to emergency medical services. On arrival, she was in altered sensorium, vitals stable, pupils bilaterally equal, and reacting to the light. Glasgow Coma Scale was 11/15 (E3M5V3). Local examination revealed about $1 \mathrm{~cm} \times 0.5 \mathrm{~cm}$ size wound over the right posterior frontal

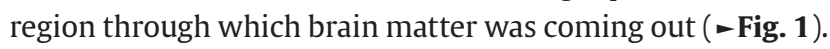
Computed tomography (CT) brain revealed linear intracerebral hemorrhage along the iron rod's track with a depressed fracture ( - Fig. 2). She received initial essential medical management and surgery for the compound depressed fracture. She recovered without neurological deficit.

published online July 29, 2021
DOI https://doi.org/

$10.1055 / \mathrm{s}-0041-1732786$ ISSN 0973-0508

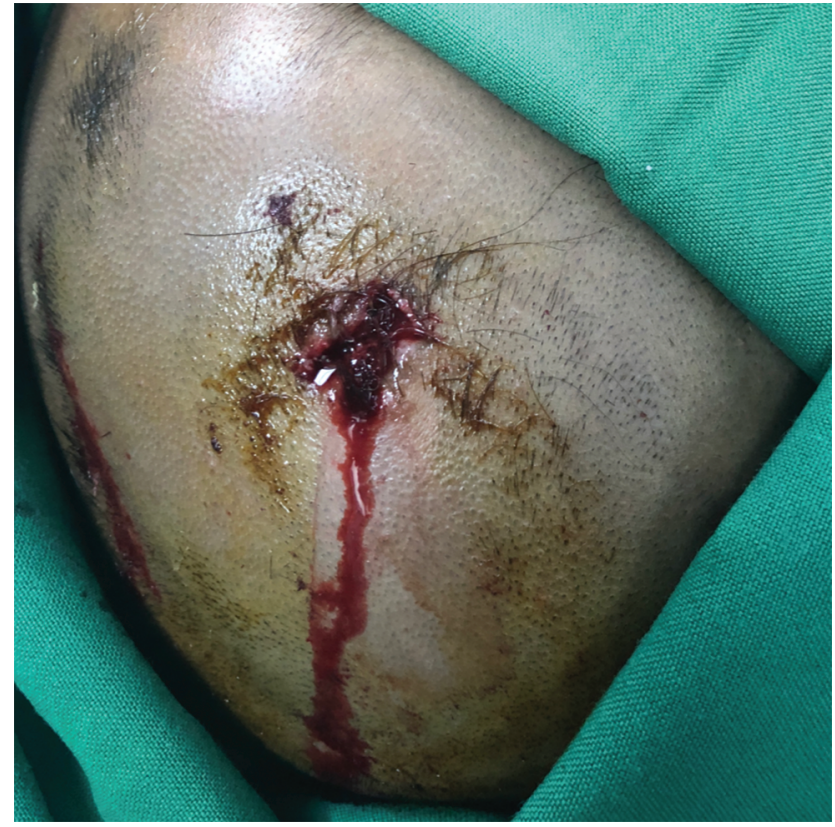

Fig. 1 Clinical photograph showing small puncture wound over right frontal region.
(C) 2021. Neurotrauma Society of India.

This is an open access article published by Thieme under the terms of the Creative Commons Attribution-NonDerivative-NonCommercial-License, permitting copying and reproduction so long as the original work is given appropriate credit. Contents may not be used for commercial purposes, or adapted, remixed, transformed or built upon. (https://creativecommons.org/licenses/by-nc-nd/4.0/).

Thieme Medical and Scientific Publishers Pvt. Ltd. A-12, 2nd Floor, Sector 2, Noida-201301 UP, India 


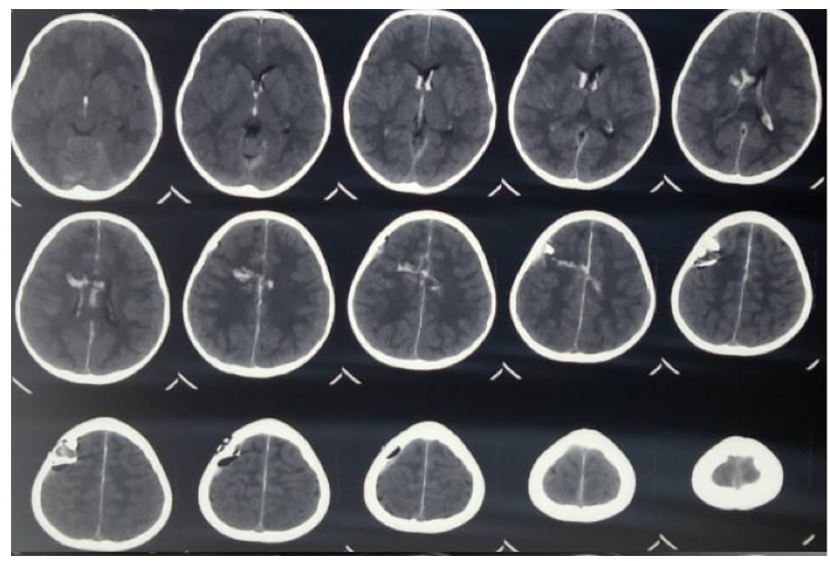

Fig. 2 CT scan brain plain study showing right frontal depressed fracture with hemorrhage along the course of iron rod with pneumocephalus and intraventricular blood.

The pattern of TBI in pediatric patients differs from an adult because of the distinctive anatomy in children, including thinner cranial bones, nonpneumatization of air sinuses, large head-to-body ratio, and less myelinated neural tissue. Thin bones in pediatric patients with low-velocity trauma can lead to significant PBI. ${ }^{1}$

Causes of PBI in pediatric patients are fall from a height over an object, hit by an object, road traffic accidents, or trauma caused by other household materials. Presenting neurological status depends on the severity of injury and damage to the underlying brain. ${ }^{3}$

CT scan imaging of the brain is the primary modality used for the assessment of PBI. ${ }^{4}$ Angiography is essential for vascular injury, depending upon the trajectory of the wound. Magnetic resonance imaging (MRI) is not essential in the initial evaluation of PBI and is contraindicated when ferromagnetic substances are present. ${ }^{5}$

Management of PBI includes hemodynamic stabilization, empirical prophylactic intravenous antibiotics, antiseizure medication, tetanus prophylaxis, antiedema measures, and local wound care. The role of surgery in PBI comprises safe removal of the penetrating object, repair of damaged structures in the trajectory of penetrating object, debridement of wound, superficial clots evacuation, achieving hemostasis, and adequate coverage for dura and scalp.

PBI is associated with significant complications. Primary complications like intracerebral hematomas, cerebral contusions, central nervous system (CNS) infection, cerebrospinal fluid (CSF) leak, or vascular injury. Secondary complication includes cerebral ischemia due to vascular injury, seizures, and infection. Infectious complications include cerebritis, meningitis, or abscess formation..$^{5}$ Staphylococcus aureus is the most common bacterial organism involved; other microorganisms include gram-negative bacilli, anaerobes, and Clostridium species. Intravenous vancomycin, ceftriaxone, and metronidazole are the most standard empirical prophylactic antibiotics used for 7 to 14 days. ${ }^{5}$ Early debridement reduces the risk of infection and chances of abscess formation. Seizures can occur due to direct cortical and subcortical brain injury resulting in scar formation. The prophylactic use of anticonvulsant treatment suggested reducing early seizures. Vascular complications can occur after a week like a pseudoaneurysm and arteriovenous fistula for that CT angiogram/Digital Subtraction Angiography (DSA) is recommended after 2 to 3 weeks. ${ }^{6}$

PBI in children constitutes only a tiny part of the total number of TBI cases. Prognosis depends on the mechanism of injury, presenting neurological status, parts of the brain affected, and prompt surgical intervention.

\section{Funding \\ None.}

\section{Conflict of Interest}

None declared.

\section{References}

1 Sookplung P, Vavilala MS. What is new in pediatric traumatic brain injury? Curr Opin Anaesthesiol 2009;22(5):572-578

2 Bakay L, Glasauer FE, Grand W. Unusual intracranial foreign bodies. Report of five cases. Acta Neurochir (Wien) 1977; 39(3-4):219-231

3 Kotecha N, Diyora B, Patil S, Giri S, Raka A, Sharma A. Key in brain: an interesting case of civilian penetrating head injury. Indian J Neurotrauma 2016;13:46-49

4 Das JM, Chandra S, Prabhakar RB. Penetrating brain injury with a bike key: a case report. Ulus Travma AcilCerrahi Derg 2015;21(6):524-526

5 Hengzhu Z, Enxi X, Lei S, Xiaodong W, Lun D. A rare case of penetrating brain injury by crossbow in a 22-month-old child. Pediatr Emerg Care 2014;30(6):421-423

6 Zyck S, Toshkezi G, Krishnamurthy S, et al. Treatment of penetrating nonmissile traumatic brain injury: case series and review of the literature. World Neurosurg 2016;91:297-307 